\title{
Simple Additive Weighting untuk Front-end Framework Terbaik
}

\author{
Lestari Yusuf ${ }^{\mathrm{a}, 1}$, Taufik Hidayatulloh ${ }^{\mathrm{b}, 2,}$, , Dini Nurlaela ${ }^{\mathrm{b}, 3}$, Lila Dini Utami ${ }^{\mathrm{b}, 4}$ dan Fuad Nur Hasan ${ }^{\mathrm{b}, 5}$ \\ ${ }^{a}$ Sekolah Tinggi Manajemen Informatika dan Komputer Nusa Mandiri, Jln. Jatiwaringin Raya No. 02 RT.08 RW.013 \\ Kelurahan Cipinang Melayu Kecamatan Makassar, Jakarta Timur, 13620, Indonesia \\ ${ }^{b}$ Universitas Bina Sarana Informatika, Jl. Kramat Raya No. 98, Senen. Jakarta Pusat 10450, Indonesia \\ ${ }^{1}$ lestari.lyf@nusamandiri.ac.id; ${ }^{2}$ taufik.tho@bsi.ac.id; ${ }^{3}$ dini.dur@bsi.ac.id; ${ }^{4}$ lila.ldu@bsi.ac.id; ${ }^{5}$ fuad.fnu@bsi.ac.id \\ *corresponding author
}

\section{INFORMASI ARTIKEL ABSTRAK}

\begin{tabular}{lll}
\hline Diterima & $:$ 26 Juni 2020 & Aplikasi web berbasis dekstop beberapa tahun terakhir ini mendapatkan \\
Diulas & $: 23$ Juli 2020 & permintaan besar yang menginginkan area ini agar lebih canggih dan kompleks, \\
Direvisi $: 29$ Juli 2020 & bukan hanya itu tetapi pengguna menginginkan aplikasi web dapat dijalankan di \\
Diterbitkan & :27 Agustus 2020 & mobile device. Tampilan web yang hanya didesain untuk perangkat komputer \\
& menyebabkan pengguna kesulitan saat membuka tampilan sebuah halaman web \\
KataKunci: & di device yang berbeda. Melalui framework front-end, web developer membantu \\
Framework Terbaik & pengguna membuat program menjadi lebih responsif dan dapat dijalankan \\
Front-end Framework & diberbagai open source seperti windows, ios, dan android. Sistem pengambilan \\
Simple Additive Weighting & keputusan yang dapat menentukan framework front-end terbaik bisa menjadi \\
& alternatif pemecahan masalah para web developer dalam menentukan framework \\
& front-end mana yang lebih mudah dan nyaman untuk digunakan. Simple Additive \\
& Weighting digunakan untuk menganalisa dan memutuskan alternatif mana yang \\
& terbaik dengan perhitungan yang mengambil lima kriteria utama dalam penelitian \\
& ini yaitu Preprocessor, Responsive, Browser Support, Easy to Use dan Template. \\
& Dalam penelitian ini prefensi tertinggi diperoleh oleh Bootstrap 1,000 sedangkan \\
& untuk Foundation dan Bulma mendapatkan prefensi sebesar 0,868 dan $0,820$.
\end{tabular}

Keywords:

Best Framework

Front-end Framework

Simple Additive Weighting

\begin{abstract}
Web applications that used to run on a desktop in recent years have received huge demand for this area to be more sophisticated and complex, not only that, but users also want web applications to run on mobile devices. Web appearance that is only designed for computer devices will make users difficult when opening a web page display on a different device. By using the CSS framework library, web developers will be greatly helped in making the program more responsive and can also be run on a variety of Open Source both Windows, iOS, and Android. Decision-making system that can determine the best front-end Framework can be an alternative solution for web developers to determine which front-end framework is easier and more convenient to use. Simple Additive Weighting is used to analyze and decide which the best alternative with calculations that take five main criteria in this research that is Preprocessor, Responsive, Browser Support, Easy to Use, and Template. In this study the highest prefence was obtained by Bootstrap 1,000 while Foundation and Bulma received prefensi of 0.868 and 0.820 .
\end{abstract}

This is an open access article under the $\underline{\mathrm{CC}-\mathrm{BY}-\mathrm{SA}}$ license.

\section{Pendahuluan}

Aplikasi web yang biasa dijalankan di sebuah dekstop beberapa tahun terakhir ini mendapatkan permintaan besar yang menginginkan area ini agar lebih canggih dan kompleks, bukan hanya itu tetapi pengguna menginginkan aplikasi web dapat dijalankan di mobile device [1]. Banyaknya keluaran perangkat mobile yang baru dengan ukuran layar yang berbeda-beda menjadikan masalah untuk para developer web, yang akhirnya membutuhkan sebuah desain web yang responsif. Tujuan dari desain yang responsif adalah untuk membangun halaman web yang dapat mendeteksi ukuran layar pengunjung sebuah web dan diikuti dengan perubahan layoutnya [2]. 
Salah satu diantara faktor utama yang harus direncanakan dengan baik agar sebuah website dapat berjalan dengan tampilan yang tetap rapih, cepat dan dapat diakses oleh berbagai macam browser dan perangkat lunak yang berbeda-beda adalah melakukan rancang bangun dari tampilan sebuah web [3]. Beberapa model Framework mampu menjawab keinginan para pengguna website dan developer yang memiliki masalah pengembangan sebuah website dan desain. Terdapat banyak sekali framework CSS yang dapat membantu developer web [4]. Pada penelitin ini membandingkan Framework Bulma yang baru saja release pada tahun 2018 yang mendapatkan react 39.779 star (https://github.com/jgthms/bulma). Bulma memiliki Flexbox yang merupakan unggulan didalam framework, framework yang didirikan 2018 ini menyajikan framework front-end yang menyediakan berbagai fitur dan komponen yang dibutuhkan [5].

Selanjutnya Framework Foundation yang mendapatkan react pada github.com sebanyak 28.265 star (https://github.com/foundation/foundation-sites). Kerangka kerja yang didirikan oleh ZURB di California ini menggunakan SASS sebagai pre-processor yang membuat tulisan terorganisasi dengan baik dan kerangka kerja ini mempermudah para developer web dengan mengutamakan responsifnya [6].

Sejak 2011 Framework Bootstrap yang dirilis mendapatkan reaksi pada github.com sekitar 140.848 star. Bootstap merupakan framework yang digunakan untuk membangun tatap muka para web developer, dibangun dengan menggabungkan java script dan css bootstrap memenuhi kebutuhan komponen yang penting untuk para developer [7]. Terhitung 48 framework yang terdapat di github.com sejak pertama kali framework CSS ditemukan diantara tahun 2000 sampai 2018. Pada tahun 2019 terdapat 4 framework terbaru. Berikut struktur bootstrap yang diperlihatkan pada Gambar 1.

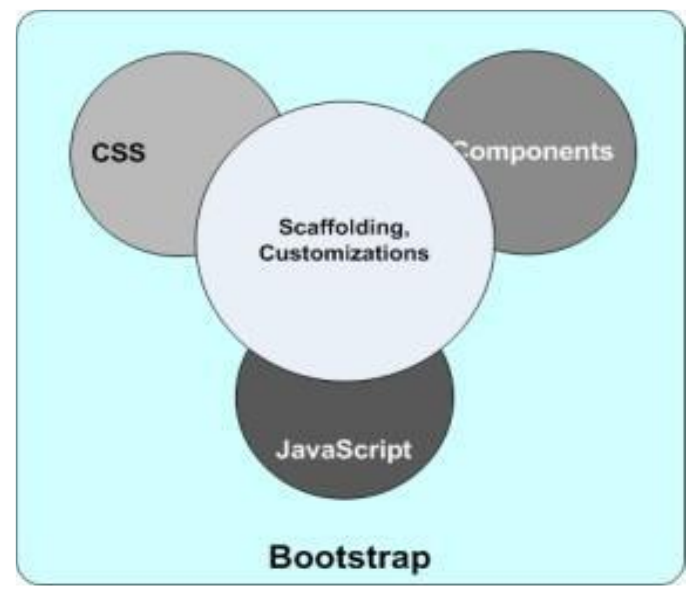

Gambar 1. Struktur Bootstrap

Semakin meningkatnya framework library CSS yang bermunculan maka, pemilihan framework library CSS dapat membantu para developer web atau para programmer muda untuk memilih framework library CSS terbaik untuk digunakan. Penelitian sebelumnya telah dilakukan pengulasan perbedaan antara framework frontend CSS [2]. Beberapa penelitian telah menampilkan beberapa front-end framework yang dapat membuat proses pembuatan sebuah web lebih mudah yang berfokus pada analisa yang efektif antara Bootstrap dan Foundation [8].

Pengujian sensitifitas bertujuan membantu pengambilan keputusan berdasarkan nilai alternatif terbaik menggunakan metode Multiple Attribute Decision Making (MDAM) yang mana membandingkan antara weighted product (WP). Simple Additive Weighting dapat digunakan sebagai penentuan nilai tertinggi untuk kelayakan angkutan umum [8]. Pada penelitian sebelumnya metode SAW digunakan untuk melakukan seleksi anggota tari [9], selain itu pada penelitian sebelumnya Simple addtive weighting (SAW) digunakan untuk memutuskan penerima kartu indonesia pintar [10]. Penelitian ini melakukan perhitungan dari setiap bobot kriteria yang diambil agar mendapatkan hasil berupa perankingan dari setiap framework front end Bootstrap, Foundation dan Bulma dalam mendapatkan framework front end yang terbaik.

\section{Metode}

Pada beberapa penelitian sebelumnya, metode SAW sering dikenal sebagai metode penjumlah dari sebuah bobot. Simple Additive Weighting (SAW) merupakan metode yang dianggap sangat intuisi dan memiliki cara yang mudah dalam menyelesaikan masalah pengambilan keputusan dengan banyak kriteria [11]. Proses normalisasi matriks keputusan pada metode SAW merupakan tahap untuk mendapatkan nilai alternatif $\left(\mathrm{A}_{\mathrm{i}}\right)$ yang terpilih dengan cara menghitung skala dan membandingkannya dengan nilai tertinggi dari seluruh alternatif yang ada [12]. Metode penelitian ini dilakukan untuk menentukan framework Front-end terbaik seperti yang dijelaskan pada Gambar 2. 


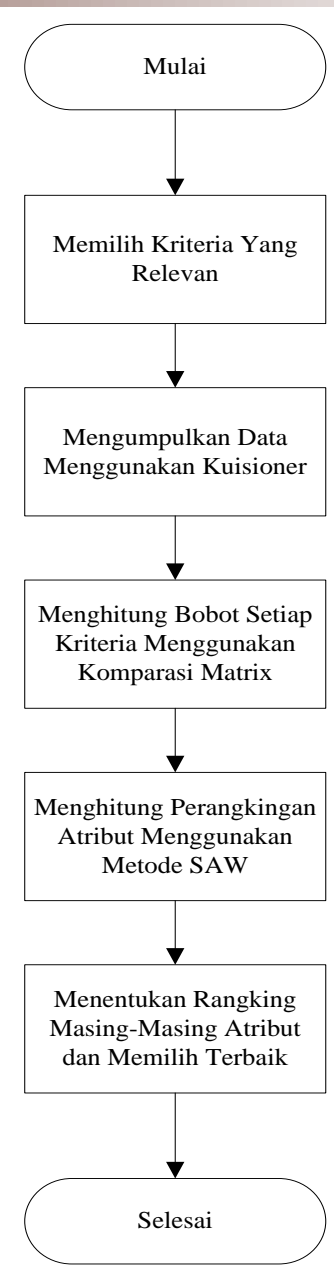

Gambar 2. Metode Penelitian Pemilihan Framework Front-end Terbaik

Langkah pertama yang harus dilakukan untuk menyelesaikan metode SAW ini adalah menentukan kriteria yang akan digunakan dan ditentukan jenis kriteria termasuk kedalam benefit atau cost [13]. Kriteria yang digunakan dijabarkan pada Tabel 1.

Tabel 1. Kriteria

\begin{tabular}{lll}
\hline C1 & Prepoccessor & benefit \\
\hline C2 & Responsive & benefit \\
\hline C3 & Browser Support & benefit \\
\hline C4 & Easy to use & benefit \\
\hline C5 & Tamplate/layout & benefit
\end{tabular}

Langkah berikutnya adalah pencarian bobot untuk setiap kriteria. Pencarian bobot kriteria ini akan membandingkan matriks dari setiap kriteria dengan objektif menggunakan perhitungan fuzzy skala 1-5 yang hasil perhitungan bobotnya diperoleh dari para pengambil keputusan dan dijelaskan pada Tabel 2.

Tabel. 2. Nilai Bobot Setiap Kriteria

\begin{tabular}{cc}
\hline Prepoccessor & 0.190 \\
\hline Responsive & 0.290 \\
\hline Browser support & 0.340 \\
\hline Easy to Use & 0.110 \\
\hline Tamplate/layout & 0.070 \\
\hline
\end{tabular}


Setelah mendapatkan bobot selanjutnya adalah proses pembuatan matriks keputusan berdasarkan kriteria kemudian dinormalisasi [14]. Berikut perhitungan proses perankingan:

a. Formula untuk normalisasi menggunakan persamaan (1)

$$
r_{i j}=\left\{\begin{array}{c}
\frac{x_{i j}}{M a x x_{i j}}, \text { Jika } j \text { adalah atribut keuntungan (benefit) } \\
\frac{\operatorname{Min} x_{i j}}{x_{i j}}, \text { Jika } j \text { adalah atribut biaya (cost) }
\end{array}\right.
$$

Dimana :

$$
\begin{aligned}
& r_{i j}=\text { Rating kinerja normalisasi } \\
& \text { Max } x_{i j}=\text { nilai maksimum dari setiap baris dan kolom } \\
& \text { Min } x_{i j}=\text { nilai minimum dari setiap baris dan kolom } \\
& x i j=\text { baris dan kolom matriks } \\
& i=1,2,3, \ldots m \\
& j=1,2,3, \ldots n
\end{aligned}
$$

b. Formula untu menghitung nilai preferensi

Nilai preferensi untuk setiap alternatif menggunakan persamaan (2)

Dimana :

$$
v_{i}=\sum_{j=1}^{n} w_{j} r_{i j}
$$

$v_{i}=$ nilai akhir dari alternatif

$w_{i}=$ bobot yang telah ditentukan

\section{Hasil dan Pembahasan}

Perhitungan di atas menjelaskan kepentingan setiap kriteria dan yang mendapatkan bobot yang lebih besar menandakan bahwa kriteria tersebut lebih penting. Setelah mendapat bobot setiap kriteria, langkah berikutnya yang harus dilakukan adalah memberikan nilai untuk setiap kriteria.

Rata-rata untuk nilai Preprocessor dibagi kedalam 3 angka fuzzy. Nilai yang akan dijadikan bobot merupakan bilangan fuzzy yang di ubah kedalam bilangan crips, dimana bilangan crips sendiri memiliki makna teori dimana jika angka mendekati 0 maka memiliki tingkat ketergantungan yang rendah, dan jika angka mendekati 1 maka tingkat ketergantungan menjadi lebih tinggi [15] dan untuk kriteria Preprocessor memiliki 3 angka fuzzy yaitu Kurang Baik (KB), Baik (B) dan Sangat Baik (SB) yang diperlihatkan pada Tabel 3.

Tabel 3. Nilai Kriteria Preprocessor

\begin{tabular}{llc}
\hline \multicolumn{1}{c}{ Rentang nilai } & \multicolumn{1}{c}{ Angka Fuzzy } & Nilai \\
\hline Tidak Ada Preprocessor & Kurang Baik & $0 /(3-1)=0$ \\
\hline Hanya Less or sass & Baik & $1 /(3-1)=0,5$ \\
\hline Less\&Sass & Sangat Baik & $2 /(3-1)=1$ \\
\hline
\end{tabular}

Rata-rata untuk nilai kriteria Responsive dibagi kedalam 2 angka Fuzzy yaitu Tidak dan Ya. Nilai yang dihasilkan diperlihatkan pada Tabel 4.

Tabel 4. Nilai Kriteria Responsive

\begin{tabular}{lcc}
\hline Rentang Nilai & Angka Fuzzy & Nilai \\
\hline tidak responsive & no & 0.000 \\
\hline responsive & yes & 1.000 \\
\hline
\end{tabular}

Kriteria yang memiliki nilai

bobot paling tinggi, rata-rata browser support dibagi kedalam 5 angka fuzzy, Sangat Buruk (SB), Buruk(B), Cukup Baik(CB), Baik(B) dan Baik Sekali(BS). Nilai untuk Browser Support dijabarkan pada Tabel 5 dibawah ini.

Tabel 5. Nilai Kriteria Browser Support

\begin{tabular}{lll}
\hline Rentang Nilai & Angka Fuzzy & Nilai \\
\hline 0 Browser dan Os & very bad & $0 / 4=0$
\end{tabular}




\begin{tabular}{lll}
\hline Rentang Nilai & Angka Fuzzy & Nilai \\
\hline 1-3 Browser dan OS & bad & $1 / 4=0.250$ \\
\hline 4-5 Browser dan OS & good enough & $2 / 4=0.500$ \\
\hline 4-6 Browser dan OS & good & $3 / 4=0.75$ \\
\hline 6 - n Browser dan OS & very good & $4 / 4=1$ \\
\hline
\end{tabular}

Kriteria Easy To Use di berikan bobot yang tidak begitu tinggi karena pada dasarnya hampir semua Frontend Framework mudah digunakan. Pada penelitian ini rata-rata nilai untuk kriteria Easy to Use dibagi ke dalam 5 angka Fuzzy. Angka tersebut dijelaskan pada Tabel 6.

Tabel 6. Nilai Kriteria Easy to Use

\begin{tabular}{lll}
\hline Rentang Nilai & Angka Fuzzy & Nilai \\
\hline $0-30$ & very hard & $0 / 4=0$ \\
\hline $31-40$ & hard & $1 / 4=0.250$ \\
\hline $41-68$ & easy enough & $2 / 4=0.500$ \\
\hline $69-80$ & easy & $3 / 4=0.75$ \\
\hline $81-100$ & very easy & $4 / 4=1$ \\
\hline
\end{tabular}

Kriteria Easy to Use, kriteria Template atau Layout pun dibagi kedalam 5 angka fuzzy, yaitu Buruk Sekali (BS), Buruk (B), Cukup Baik (CB), Baik (B) dan Baik Sekali (BS). Data dideskripsikan pada Tabel 7.berikut:

Tabel 7.Nilai Kriteri Template/Layout

\begin{tabular}{lll}
\hline Rentang Nilai & Angka Fuzzy & Nilai \\
\hline $0-30$ & very bad & $0 / 4=0$ \\
\hline $31-40$ & bad & $1 / 4=0.250$ \\
\hline $41-68$ & good enough & $2 / 4=0.500$ \\
\hline $69-80$ & good & $3 / 4=0.75$ \\
\hline $81-100$ & very good & $4 / 4=1$ \\
\hline
\end{tabular}

Setelah itu, langkah berikutnya adalah mendapatkan data nilai yang memenuhi dari setiap alternatif yang akan dibandingkan. Data diisi oleh para pengambil keputusan yang dijelaskan pada Tabel 8.

Tabel 8. Nilai Alternatif untuk setiap Kriteria

\begin{tabular}{llllll}
\hline $\begin{array}{l}\text { Pembobotan } \\
\text { Alternatif }\end{array}$ & C1 & C2 & C3 & C4 & C5 \\
\hline A1 (Foundation) & Sass & Ya & 1.000 & 68 & 75 \\
\hline A2 (Bootstrap) & Less dan Sass & Ya & 1.000 & 80 & 80 \\
\hline A3 (Bulma) & Less & Ya & 0.750 & 78 & 78 \\
\hline
\end{tabular}

Angka-angka tersebut dikonversi kedalam bilangan kedalam bilangan matriks data akan dideskripsikan pada matriks.

$$
\left[\begin{array}{lllll}
0.500 & 1.000 & 1.000 & 0.500 & 0.750 \\
1.000 & 1.000 & 1.000 & 0.750 & 0.750 \\
0.500 & 1.000 & 0.750 & 0.750 & 0.750
\end{array}\right]
$$

Setelah melakukan konversi bilangan, maka langkah berikutnya adalah melakukan perhitungan normalisasi untuk setiap alternatif. Pada tahap ini, jika bobot dari kriteria semakin besar semakin baik, maka gunakan perhitungan kriteria benefit [11].

Alternatif 1

$$
r 11=\frac{0.500}{\max \{0.500 ; 1.000 ; 0.500\}}=\frac{0.500}{1.000}=0.500
$$




$$
\begin{aligned}
& r 12=\frac{1.000}{\max \{1.000 ; 1.000 ; 1.000\}}=\frac{1.000}{1.000}=1.000 \\
& r 13=\frac{1.000}{\max \{1.000 ; 1.000 ; 0.750\}}=\frac{1.000}{1.000}=1.000 \\
& r 14=\frac{0.500}{\max \{0.500 ; 0.750 ; 0.750\}}=\frac{0.500}{0.750}=0.667 \\
& r 15=\frac{0.750}{\max \{0.750 ; 0.750 ; 0.750\}}=\frac{0.750}{0.750}=1.000
\end{aligned}
$$

\section{Alternatif 2}

$$
\begin{aligned}
& r 21=\frac{1.000}{\max \{0.500 ; 1.000 ; 0.500\}}=\frac{1.000}{1.000}=1.000 \\
& r 22=\frac{1.000}{\max \{1.000 ; 1.000 ; 1.000\}}=\frac{1.000}{1.000}=1.000 \\
& r 23=\frac{1.000}{\max \{1.000 ; 1.000 ; 0.750\}}=\frac{1.000}{1.000}=1.000 \\
& r 24=\frac{0.750}{\max \{0.500 ; 0.750 ; 0.750\}}=\frac{0.750}{0.750}=1.000 \\
& r 25=\frac{0.750}{\max \{0.750 ; 0.750 ; 0.750\}}=\frac{0.750}{0.750}=1.000
\end{aligned}
$$

$\underline{\text { Alternatif } 3}$

Normalisasi Matriks

$$
\begin{aligned}
& r 31=\frac{0.500}{\max \{0.500 ; 1.000 ; 0.500\}}=\frac{0.500}{1.000}=0.500 \\
& r 32=\frac{1.000}{\max \{1.000 ; 1.000 ; 1.000\}}=\frac{1.000}{1.000}=1.000 \\
& r 33=\frac{0.750}{\max \{1.000 ; 1.000 ; 0.750\}}=\frac{0.750}{1.000}=0.750 \\
& r 34=\frac{0.750}{\max \{0.500 ; 0.750 ; 0.750\}}=\frac{0.750}{0.750}=1.000
\end{aligned}
$$

$$
\left[\begin{array}{lllll}
0.500 & 1.000 & 1.000 & 0.667 & 1.000 \\
1.000 & 1.000 & 1.000 & 1.000 & 1.000 \\
0.500 & 1.000 & 0.750 & 1.000 & 1.000
\end{array}\right]
$$

Setelah dilakukan perhitungan antara bobot setiap kriteria $(w)$ dan normalisasi matrik hasil perhitungandari setiap alternatif $(r)$ untuk mendapatkan nilai prevensi $(v i)$. berikut Nilai $w$ yang digunakan untuk setiap bobot kriteria:

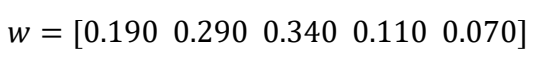

$$
\begin{aligned}
& V 1=(0.500 \times 0.190)+(1.000 \times 0.290)+(1.000 \times 0.340)+(0.667 \times 0.110)+(1.000 \times 0.070)=0.868 \\
& V 2=(1.000 \times 0.190)+(1.000+0.290)+(1.000 \times 0.340)+(1.000 \times 0.110)+(1.000 \times 0.070)=1.000 \\
& V 3=(0.500 \times 0.190)+(1.000+0.290)+(0.750 \times 0.340)+(1.000 \times 0.110)+(1.000 \times 0.070)=0.820
\end{aligned}
$$

Nilai tertinggi dari tiga alternatif tersebut dari penjumlahan matriks. Peringkat ditunjukkan pada Tabel 9. 
Tabel 9. Peringkat Front-end Framework

\begin{tabular}{lcc}
\hline \multicolumn{1}{c}{ Alternatif } & Nilai prefensi (Vi) & Ranking \\
\hline A1(Foundation) & 0.862 & 2 \\
\hline A2(Bootstrap) & 1.000 & 1 \\
\hline A3(Bulma) & 0.820 & 3 \\
\hline
\end{tabular}

Setiap bobot kriteria dari alternatif dan dihitung menggunakan metode Simple Additive Weighting (saw) maka hasil dari penelitian ini akan memudakan web developer dalam hal pemilihan front-end framework terbaik yang akan digunakan atau bahkan yang berencana akan mengkombinasikan front-end framework tersebut, karena kriteria-kriteria pada penelitian ini sudah dapat mewakili kebutuhan-kebutuhan front-ent framework yang disesuaikan dengan web developer. Sementara kekurangan yang ada pada penelitian ini terdapat pada alternatif yang digunakan hanya untuk tiga alternatif front-ent framework saja.

\section{Kesimpulan dan Saran}

Perhitungan yang dilakukan menggunakan metode Simple Additive Weighting dengan menggunakan lima kriteria yang jika bobot kriterianya diurutkan akan didapat bobot terbesarnya adalah kriteria browser support, responsive, preprocessor, easy to use dan yang terakhir adalah template/layout, maka diperoleh urutan front-end framework terbaik, yang pertama yaitu bootstrap yang mendapatkan nilai prefensi sebesar 1.000, Foundation dengan nilai prefensi sebesar 0.868 dan Bulma mendapatkan nilai prefensi sebesar 0.820. Pada penelitian berikutnya kami menyarankan agar lebih memperdalam kriteria-kriteria dari framework front-end tersebut. Penelitian dapat dilakukan menggunakan metode-metode pengambilan keputusan lain, serta mengkomparasi dengan metode yang lainnya.

\section{Daftar Pustaka}

[1] B. Vukelic, "Comparison of front-end frameworks for web applications development 4," Zb. Veleuc. u rijeci, vol. 6, no. 1, pp. 261-282, 2018.

[2] N. Jain, "Review Of Different Responsive CSS Front-End Frameworks," J. Glob. Res. Comput. Sci., vol. 5, no. 11, pp. 5-10, 2014.

[3] A. Zakir, "Rancang bangun responsive web layout dengan menggunakan bootstrap framework," $J$. Nas. Inform. dan Teknol. Jar., vol. 1, no. 1, pp. 7-10, 2016.

[4] J. O. Meiert, The Little Book of HTML / CSS Frameworks. United States of America: O'Reilly Media, 2015.

[5] G. Gunadi, "Pengembangan aplikasi web berbasis flexbox untuk pengelolaan jadwal produksi dan dokumen digital menggunakan framework bulma di PT. Gramedia," Infotech, vol. 5, no. 2, pp. 40-47, 2019.

[6] S. Anugerah, "Pemodelan responsive web menggunakan foundation framework dalam pengembangan perangkat lunak," vol. 2013, no. semnasIF, pp. 230-236, 2013.

[7] B. Jacobus and J. Marah, Mastering Boostrap 4, Second. Brimingham: PACKT Publishing Ltd., 2018.

[8] N. S. Nekida, R. A. Saputra, L. S. Ramdhani, and T. Hidayatulloh, "implementasi e-ticketing uji kelayakan kendaraan bermotor untuk meningkatkan pelayanan publik," J. SWABUMI, vol. 6, no. 2, pp. 143-148, 2018.

[9] H. Adela, K. A. Jasmi, B. Basiron, M. Huda, and A. Maseleno, "Selection of dancer member using simple additive weighting," Int. J. Eng. Innov. Technol., no. June, 2018.

[10] A. Saryoko, S. Muttaqin, and R. Hidayat, "sistem penunjang keputusan penerima kartu indonesia pintar menggunakan metode simple additive weighting ( SAW )," J. Tek. Komput., vol. V, no. 2, pp. 139$146,2019$.

[11] G.-H. Tzeng and J.-J. H. Huang, Multiple Attribute Decision Making Methods Anda Applications. New York. Taylor \& Francis Group, an Informa business., 2011.

[12] M. A. Mude, "PADA KASUS UMKM," vol. 8, no. Agustus, pp. 76-81, 2016.

[13] D. F. Shiddieq and E. Septyan, "analisis perbandingan metode ahp dan saw dalam penilaian kinerja karyawan (studi kasus di PT. Grafindomedia Pratama Bandung)," J. LPKIA, vol. 10, no. 2, 2017.

[14] N. C. Resti, "Penerapan metode simple additive weighting ( saw ) pada sistem pendukung keputusan pemilihan lokasi untuk Cabang Baru Toko," J. INTENSIF, vol. 1, no. 2, pp. 102-107, 2017.

[15] S. Suhada, T. Hidayatulloh, and S. Fatimah, "Penerapan fuzzy madm model weighted product dalam pengambilan keputusan kelayakan penerimaan kredit di BPR Nusamba Sukaraja ( The Application of Fuzzy MADM Model Weighted Product in Decisions Support of Credit Worthiness in the BPR Nusamba Sukaraja )," JUITA, vol. VI, pp. 61-71, 2018. 